\title{
Dead Fœtale in Utéro: Hospitable Frequency, Etiologies and Maternal Prognosis to the Service of Obstetric Gynecology of the Hospital National Donka, CHU of Conakry, Guinea
}

\author{
Boubacar Siddi Diallo" ${ }^{*}$, Abdourahmane Diallo², Ibrahima Sory Balde ${ }^{2}$, \\ Mamadou Hady Diallo', Ibrahima Conte ${ }^{2}$, Ousmane Balde ${ }^{1}$, Ibrahima Sylla ${ }^{2}$, \\ Diakaria Daou Sidibe1, Telly Sy², Namory Keita ${ }^{1}$ \\ ${ }^{1}$ University Department of Gynecology-Obstetrics, Donka National Hospital, Conakry, Guinea \\ ${ }^{2}$ University Department of Gynecology-Obstetrics, Ignace Deen National Hospital, Conakry, Guinea \\ Email: ^tounty1@yahoo.fr, adiallo69gn@yahoo.fr, baldeisory@yahoo.fr, hadydiallo@yahoo.fr, conteib1976@gmail.com, \\ baldeousmane04@gmail.com,dribra62@yahoo.fr, camarahawa2002@gmail.com,diakariadaouP42@gmail.com, sytelly@yahoo.fr, \\ namoryk2010@yahoo.fr
}

How to cite this paper: Diallo, B.S., Diallo, A., Balde, I.S., Diallo, M.H., Conte, I., Balde, O., Sylla, I., Sidibe, D.D., Sy, T. and Keita, N. (2019) Dead Fœtale in Utéro: Hospitable Frequency, Etiologies and Maternal Prognosis to the Service of Obstetric Gynecology of the Hospital National Donka, CHU of Conakry, Guinea. Open Journal of Obstetrics and Gynecology, 9, 539-546. https://doi.org/10.4236/ojog.2019.94053

Received: March 28, 2019

Accepted: April 25, 2019

Published: April 28, 2019

Copyright $\odot 2019$ by author(s) and Scientific Research Publishing Inc. This work is licensed under the Creative Commons Attribution International License (CC BY 4.0).

http://creativecommons.org/licenses/by/4.0/ (c) (i) Open Access

\begin{abstract}
Objectives: The objectives of this work were to calculate the frequency of MFIU, to describe the epidemiological profile, to identify the étiologies and to establish the maternal prognosis. Methodology: It was about a prospective survey of analytic type spreading on one period of twelve (12) month achieved to the service of Obstetric Gynecology of the hospital National Donka, FALLEN from Conakry. Results: On 5226 childbirths, we recorded 208 cases of MFIU, either a frequency of $3.98 \%$. The epidemiological profile was the one of a teenager or aged woman (more of 35 ans) with respectively $(8.17 \%)$ and (7.20\%), sans follow-up prénatal $(10.41 \%)$, nullipare $(6.02 \%)$, célibataire $(7.80 \%)$, ménagère (5.02\%) and non scolarisée (5.16\%). The MFIU occurred in the age group of 32 - 36 SA. L'absence of the MAF was the main motive of consultation $94.23 \%$. All cases of MFIU benefitted from a confirmation scan. The vasculo-renal syndromes and their complications were the main étiologie 43.75\%; follow-up of the malaria is $13.94 \%$. The majority of the gestantes were delivered by low way $98.08 \%$. The induction of work has been made mainly to the misoprostol (Cytotec $200 \mu \mathrm{g}$ ) either $81.86 \%$ against $10.78 \%$ of Syntocinon in drip. The maternal morbidity has especially been dominated especially by the hemorrhages in the case of long length retention and the infections when the membranes are broken either $1.44 \%$ against $98.56 \%$ of case of good maternal prognosis. No maternal death has been recorded. Conclusion: The prenatal consultation offer recentered and the one of medical correct cares of the vas-
\end{abstract}


culo-renal syndromes and the malaria could reduce the cases of death fotale

efficiently in utero.

\section{Keywords}

MFIU, Frequency, Etiologie

\section{Introduction}

The World Health Organization (WHO) defines fetal death in utero (MFIU) as the fetal death with or without retention occurring from the 22nd SA with a weight $\geq 500 \mathrm{~g}$ and before any childbirth [1]. 50\% of the MFIU occur before the term, $18 \%$ after the term and a étiologie is only recovered in $40 \%$ of the cases [2]. His/her/its frequency is variable of a country to the other according to the socio-economic standard of living and the quality of hold in charge of pregnancy. She/it is highly lower to $1 \%$ in the countries médicalisés [3]. Notably: $0.35 \%$ is in Canada in 2003 [4], 0.60\% in Sweden in 2000 [5], 0.66\% in Switzerland in 2006 [6] and $0.69 \%$ in France in 2005 [7]. These relatively weak frequencies in these developed countries are on the other hand very elevated in the countries of the third world. In these countries of the third world, his/her/its frequency varies from 1\% to 5\%: $1.72 \%$ in Tunisia in 2003 [8]; 3.3\% in South Africa in 2004 [9]; $3.52 \%$ in Gabon in 1999 [10] and 4.18\% in Senegal in 2001 [8]. In Guinea, the different studies achieved in the sanitary structures between 1992 and 2008 showed the following frequencies: in the HS N Ignace Deen: $2.96 \%$ in 2008 and to the hospital national Donka: $1.80 \%$ in 1992 [11].

The MFIU represents a drama which sometimes lived badly and unsympathetically for the parents. She/it is considered as the failure of the progress and the prenatal follow-up of pregnancy by the practitioner [3]. Outraging his/her/its psychological reverberation at the parents, the MFIU poses a double problem to the practitioner: the one to drive the investigation étiologique in order to assure a best obstetric future and the one of the obstetric attitude to adapt to assure the uterine evacuation in order to warn the maternal complications [11].

The objectives of this work were to calculate the frequency of MFIU, to describe the epidemiological profile, to identify the étiologies and to establish the maternal prognosis.

\section{Methodology}

It was about a prospective survey of analytic type spreading on one period of twelve (12) month achieved to the service of Obstetric Gynecology of the hospital National Donka, FALLEN from Conakry.

All cases of MFIU have been included in this survey, diagnosed before the beginning of the childbirth work and taken in charge in the service during the period of survey.

Have been excluded of this survey, all cases of abortions (age lower to 22 
HIS/HER/ITS); the MFIU diagnosed at a woman in work (mortality per partum) and the women received for the complications of MFIU.

The studied variables were epidemiological (maternal age, consistent prenatal, gestité, parity, profession, the level of instruction, the statute matrimonial), cliniques (age gestational, motive of consultation, fashion of work induction, maternal morbidity, maternal mortality) and étiologiques

\section{Results}

Frequency: On 5226 childbirths, we recorded 208 cases of MFIU, either a frequency of $3.98 \%$.

\subsection{Epidemiology}

- Age: I picture:

\begin{tabular}{ccccccc}
\hline childbirths, & \multicolumn{2}{c}{ MFIU } & \multicolumn{5}{c}{ Fœtus Vivants } \\
\hline Age groups & efficient & $\%$ & efficient & $\%$ & RR & IC à $95 \%$ \\
\hline $\begin{array}{c}15-19 \text { years } \\
\mathrm{n}=1250\end{array}$ & 90 & 7.20 & 1160 & 92.80 & 2.43 & $1.89-3.39$ \\
$20-24$ years & 46 & 3.31 & 1344 & 96.69 & 0.75 & $0.55-1.04$ \\
$\mathrm{n}=1390$ & & & & & & \\
$25-29$ years & 16 & 1.13 & 1404 & 98.87 & 0.22 & $0.13-0.37$ \\
$\mathrm{n}=1420$ & & & & & & \\
$30-34$ years & 22 & 2.93 & 728 & 97.07 & 0.71 & $0.46-1.09$ \\
$\mathrm{n}=750$ & & & & & & \\
$\geq 35$ years & 34 & 8.17 & 82 & 1.83 & 2.26 & $1.59-3.22$ \\
$\mathrm{n}=416$ & & & & & & \\
\hline
\end{tabular}

d.d.l $=4 ; X^{2}=87.09 ; \mathrm{P}=0.003214721 ;(\mathrm{P}<0.05)$.

- Matrimonial statute: II picture:

\begin{tabular}{ccccccc}
\hline Childbirths, & \multicolumn{2}{c}{ MFIU } & \multicolumn{5}{c}{ Fœtus Vivants } \\
\hline Matrimonial statute & efficient & $\%$ & efficient & $\%$ & RR & IC à 95\% \\
\hline Bachelors & 72 & 7.80 & 852 & 92.20 & 2.46 & $1.87-3.25$ \\
$\mathrm{n}=924$ & & & & & & \\
Married & 136 & 3.16 & 4166 & 96.84 & 0.41 & $0.31-0.54$ \\
$\mathrm{n}=4302$ & & & & & & \\
\hline
\end{tabular}

d.d.l $=1 ; X^{2}=41.48 ; \mathrm{P}=0.00011057 ;(\mathrm{P}<0.05)$.

- Level of instruction: III picture:

\begin{tabular}{ccccccc}
\hline Childbirths, & \multicolumn{2}{c}{ MFIU } & \multicolumn{4}{c}{ Fœtus Vivants } \\
\hline \multirow{2}{*}{ Level of instruction } & efficient & $\%$ & efficient & $\%$ & RR & IC à $95 \%$ \\
\hline
\end{tabular}


Continued

\begin{tabular}{ccccccc}
\hline Néant & 150 & 5.16 & 2758 & 94.84 & 2.06 & $1.53-2.78$ \\
$\mathrm{n}=2906$ & & & & & & \\
Primaire & 36 & 4.50 & 764 & 95.50 & 1.16 & $0.81-1.65$ \\
$\mathrm{n}=800$ & & & & & & \\
Secondaire & 20 & 3.17 & 900 & 97.83 & 0.50 & $0.32-0.79$ \\
$\mathrm{n}=920$ & & & & & & \\
Supérieur & 02 & 0.33 & 598 & 99.67 & 0.07 & $0.02-0.30$ \\
$\mathrm{n}=600$ & & & & & & \\
\hline
\end{tabular}

d.d. $1=3 ; X^{2}=39.87 ; \mathrm{P}=0.005142131$.

- Prenatal follow-up: The patients without prenatal follow-up represented $10.41 \%$.

- Parity: The nulliparas was the more represented either $6.02 \%$.

- Profession: The housewives are the more touched either 5.02\%.

- Age gestational: The age group of 32 - 36 SA was the most interested $34.62 \%$.

- Motives of consultation: The absence of the MAF was the main motive of consultation $94.23 \%$.

- Balance decorated clinic: All cases of MFIU benefitted from a scan of confirmation (100\%).

- Fashion of childbirth: The majority of the gestantes delivered by low way $98.08 \%$.

- Medicines for the induction of work: The induction of work has been made mainly to the misoprostol (Cytotec $200 \mu \mathrm{g}$ ) either $81.86 \%$ against $10.78 \%$ of Syntocinon in drip.

- Maternal morbidity: The maternal morbidity has especially been dominated especially by the hemorrhages in the case of long length retention and the infections when the membranes are broken either $1.44 \%$ against $98.56 \%$ of case of good maternal prognosis.

- Maternal mortality: No maternal death has been recorded.

\subsection{Etiologies}

- Etiologies: The vasculo-renal syndromes and their complications were the main étiologie $43.75 \%$ follow-up of the malaria is $13.94 \%$.

\section{Discussion}

- Frequency: On 5226 childbirths, we recorded 208 cases of MFIU, either a frequency of 3.98\%. This result is intermediate between those found by Randrianaivo HS and coll, Roudrière J V, Cissé CT and coll and those returned by Martinek IT and Sefrioui OH with respectively 3.3\% [7]; 3.52\% [2]; 4.18\% [8] and $0.66 \%$ [5], $1.75 \%$ [3]. This rate raised from MFIU explains itself by the fact that the service of survey is the last recourse of the sanitary pyramid 
of the country receiving the cases of evacuations for obstetric complications.

- Age: Picture I: La MFIU doesn't save any age group; however the teenagers and the aged women (of more than 35 years) paid the biggest tribute with respectively $8.17 \%$ and $7.20 \%$. The difference is statistically meaningful ( $\mathrm{P}=$ $0.003214721)$. This report is similar to those observed by Diallo F.D with $9.54 \%$ for the aged women and $8.92 \%$ at the teenagers (of less than 20 years) [12] and Sefrioui $\mathrm{OH}$ that notes $8.36 \%$ at the women aged of more than 35 years [3]. The predominance of the aged women ( $>35$ ans) proves that age is a factor of risk of the MFIU. The frequency raised of the teenagers in our set would explain itself by the predilection of the vasculo-renal syndromes and their complications.

- Matrimonial statute: II picture: The bachelors were the more touched with a frequency of $7.80 \%$ against $3.16 \%$ at the brides. The difference is not statistically meaningful $(\mathrm{P}=0.05711057)$. This result is superimposable to those found by Hansen K.D. and of Kalenga M.K. with respectivement 7.60\% [9] and $6.98 \%$ [10]. The same observation has been made by other authors [12] [13]. On the other hand our result is contrary to the one affirmed by Viatonou R.V.G in Benin that says that the unmarried statute doesn't constitute a factor of risk of mortinatalité [14]. This predominance of the bachelors would be bound by the fact that they are often bearers of pregnancy non wanted, the most often outcast or hidden of the family, without prenatal follow-up, letting them thus vulnerable to the ominous consequences of the self-medication and the use of the decoctions.

- Level of instruction: Picture III: non schooled 5/10 gestantes developed the MFIU is a frequency of $5.16 \%$. The difference is statistically meaningful ( $\mathrm{P}=$ 0.005142131 ). In several studies, a good interrelationship between level of instruction and mortinatalité has been recovered [7] [12] [14]. Illiteracy constitutes the factor of most elevated risk of mortinatalité [12] [14]. This risk decreases with the elevation of the instruction level as J showed it. C. CALDWELL in Nigeria [14]. The predominance of the women non schooled could explain itself by the fact that they have less information concerning the health of reproduction and don't make the prenatal follow-up, escaping thus the possibilities of precocious tracking of the factors of risk of MFIU, especially correctly.

- Prenatal follow-up: The patients without prenatal follow-up represented $10.41 \%$. He/it ensues of this survey that the frequency of the MFIU decreased as the number of CPN increases passer-by thus to $1.88 \%$ in $3 \mathrm{CPN}$. Most authors are unanimous that the absence of CPN is a factor of risk of mortinatalité and maternal mortality [3] [10] [13].

- Parity: The nulliparas was the more represented either $6.02 \%$. This result is relatively close to the report of Diallo F.D 4.19\% [11]. On the other hand Vatonou R.V.G nearly finds the double in his/her/its survey $11.19 \%$ [14]. This predominance at the nullipares could generally explain itself by the predilection of the vasculo-renal syndromes and their complications for this category 
of the constituted population of teenager [3] [5] [7].

- Profession: The housewives are the more touched either 5.02\%. Our report is similar to those found by F.B. Diallo and Ndioubnane O.M.B with respectively $4.78 \%$ and $3.75 \%$. It reflects the structure of our society where the housewives are to majority illiterate with a weak income to cover the expenses of health.

- Age gestational: The age group of 32 - 36 SA was the most interested $34.62 \%$. This result is contrary to those observed by Sefrioui O. and coll [3] and Diallo F.D [11] with respectively $54.33 \%$ in the slice of $37-41$ HIS/HER/ITS and $40 \%$ for the one of $26-31$ SA. This frequency raised from MFIU in the slice of $32-36$ HIS/HER/ITS of our survey could explain itself by the fact that the majority of our gestantes had developed the mortinatalité before the term.

- Motive of consultation: The absence of the MAF was the main motive of consultation $94.23 \%$. This result is similar to the data of the literature $93.33 \%$ [13] and $89.5 \%$ [10].

- Balance decorated clinic: All cases of MFIU benefitted from a scan of confirmation (100\%). This result is superimposable to those observed by Kalenga M.K [10] and Baeta. S [15] either 100\%. This whole cover of the gestantes could explain itself by the fact that the scan was systematic in the hold in charge of MFIU in this survey and by his/her/its availability with an affordable cost in the service.

- Fashion of childbirth: The majority of the gestantes delivered by low way 98.08\%. The statistical analysis of our data is meaningful $(\mathrm{P}=0.00512763)$. This result is superimposable to the previous studies in Guinea $95.45 \%$ and 99.08\% [11]. This result could explain itself by the fact that the majority of these patients didn't have of against indication of childbirth by low way and that the Caesarean was indicated like last means of recourse.

- Medicines for the induction of work: The induction of work has been made mainly to the misoprostol (Cytotec $200 \mu \mathrm{g}$ ) either $81.86 \%$ against $10.78 \%$ of Syntocinon in drip. This result is superimposable to those found by F. B. Diallo [11] and Ndioubnana O.M.B in Nouakchott in Mauritania [12] with respectively $89.48 \%$ against $10.52 \%$ and $82.2 \%$ against $17.8 \%$.

- Maternal morbidity: The maternal morbidity has especially been dominated especially by the hemorrhages in the case of long length retention and the infections when the membranes are broken either $1.44 \%$ against $98.56 \%$ of case of good maternal prognosis. This report is comparable to the one of F.B. Diallo [11] either $1.67 \%$ against $98.33 \%$ of case of good prognosis.

- Maternal mortality: None: maternal death has not been recorded.

\section{Etiologies}

- Etiologies: The vasculo-renal syndromes and their complications were the main étiologie $43.75 \%$ follow-up of the malaria is 13.94 . Ce result is superimposable to those observed by F.B. Dialo [11] and Kalenga M.K [10] with respectively $45.75 \%$ and $46.67 \%$. Most authors agree on the fact that the vas- 
culo-renal syndromes and his/her/its complications appear to the 1st rank of the étiologies of MFIU [5] [7] [12]. This rate raised of malaria would explain itself by the fact that a lot of our patients didn't benefit from prophylactic treatment of the malaria for lack of prenatal follow-up. Otherwise the intervening of paludal access during pregnancy increases the risk of morbidity and maternal mortality and fotale [7].

\section{Conclusion}

The prenatal consultation offer recentered and the one of medical correct cares of the vasculo-renal syndromes and the malaria could reduce the cases of death fotale efficiently in utero.

\section{Conflicts of Interest}

The authors declare no conflicts of interest regarding the publication of this paper.

\section{References}

[1] Hohlfeld, P., Nbeurre, T., Lepori, L. and Corbaz, Y. (1998) Vial: The Death in Utero: Taken in Obstetric Charge. Department of Gynecology-Obstetrics. Medicine and Hygiene, 56, 807.

[2] Roudiere, J.V. (1998) Obstetric Exercise in Precarious Situation in Gabon. Notebooks of Health, 85, 325-329.

[3] Sefrioui, O.N.S., Zinoun, L., Zouad, A., Aboulfalah, N., et al. (2000) Aspect Epidemiological of the Deaths Fœtales in Utero: Motherhood Lalla Meryem, Fallen Ibn Rochd, Casablanca. Morocco Maghreb Médical, 20, 342.

[4] Mounier, B., Equime, O.H. and Devos, P. (1999) Syndrome Hypertensor of the Pregnant Woman. Physiopathologie, Definition and Complications Evolutionary Materno-Fœtales. The Medical Presses, 28, 16, 880-885.

[5] Martinek, I.E., There, V. and Hohlfed, P. (2006) Prise en charge de la mort in utero: Quel bilan proposer? Journal de Gynécologie Obstétrique et Biologie de la Reproduction, 35, 594-606. https://doi.org/10.1016/S0368-2315(06)76449-3

[6] Lansac, J., Shepherd, C. and Magnin, G. (1986) Obstetrics for the Practitioner. Simep, Paris, 117

[7] Randrianaivo, H., Syllard, B., Gerardin, B., Kauf, H., et al. (2006) Étude des 178 morts fotales in utero dans le sud de l'île de la Réunion en 2001-2004. Journal de Gynécologie Obstétrique et Biologie de la Reproduction, 35, 665-672. https://doi.org/10.1016/S0368-2315(06)76461-4

[8] Cisse, C.T., Ngoma, S.J., Martin, S.L., Diaw, C.T. and Diaohiou, F. (1997) Epidemiological Surveillance of Mortality Precocious Néonatale to It Fallen from Dakar (Senegal). Notebook Health, 7, 109-112.

[9] Hansen-Koenig, D. (1987) Prematurity, Hypotrophy and Perinatal Mortality in the Grand Duchy of Luxembourg, 1980-1982. Archives Francaises de Pediatrie, 44, 611-614.

[10] Kalenga, M.K., Mutach, K. and Odimba, F.K. (1992) Epidemiological Consideration on the Childbirths of Death Been Born to the Motherhood of Bécamine Sendwé of Lubumbashi (Rép. D. Congo). French Journal of Gynecology and Obstetrics, 871, 
26-29.

[11] Diallo, F.B., Diallo, A.B., Onivogui, G., Sy, T., Camara, F., Diallo, O.H., Diallo, M.S. and Diallo, T.S. (2002) MFIU: Frequency and Epidemiological Aspects to the Clinic of Gynéco Obstetric Ignace Deen. Fallen of Conakry Guinea Médicale, 27, 11-20.

[12] Ndioubnane Ould Mahmoud Dance (2002) Starting Point of Work by the Misoprostol Vaginal Intra in the MFIU. Service of Obstetric Gynecology. Hospital Military Nouakchott, Mauritania. Medical Morocco, 24, 56.

[13] Baeta, S.K., Akpadja, A.K.S. and Hodonou, Z.I. (1991) Etiologies of Death Fœtale in Utero about 308 Cases to the Service of Obstetric Gynéco of It Fallen from Lomé Togo. Medical Africans, 118, 16-17.

[14] Viatonou, R.V.G. (1996) Contribution to the Survey of the Perinatal Mortality about 1201 Births Recorded to the Motherhood of Cotonou. Thesis of Medicine, National University of the Benin, Abomey-Calavi, 363.

[15] Bampoky, P. (1990) Perinatal Mortality to the Center Municipal ABASS NDAO. Thesis of Medicine, University of Dakar, Dakar, 12. 